\title{
A aplicabilidade do chorume oriundo do processo de compostagem biofertlizante orgânico para agricultura sustentável
}

O objetivo deste estudo foi avaliar a eficiência do chorume, oriundo do processo de compostagem de resíduos orgânicos, em diversas porcentagens, na rega de três culturas distintas: Couve Manteiga da Geórgia (Brassica oleracea var. acephala), Pimenta Malagueta (Capsicum frutescens 'Malagueta') e grãos de Feijão (Phaseolus vulgaris). A montagem da leira ocorreu no Laboratório de Práticas Ambientais da Universidade CEUMA, sendo o período experimental de 16 de março até o dia 16 de maio de 2018, durando 60 dias, baseado em Góes et al. (2011) adaptado. Ao todo foram realizados 33 tratamentos sendo organizado da seguinte forma para cada cultura: T1 - 100\% H2O; T2 - 10\% chorume; T3 - 20\% de chorume; T4 - 30\% de chorume; T5 - $40 \%$ de chorume; T5 - 50\% de chorume; T6 - 60\% de Chorume; T7 - 70\% de Chorume; T8 - 80\% de chorume; T9 - 90\% de chorume; T10 - 100\% de chorume. O solo utilizado para o plantio das culturas teve os parâmetros físico-químicos analisadas no Laboratório de Física da Universidade Estadual do Maranhão - UEMA, seguindo a metodologia da EMBRAPA, 2017. As análises físico-químicas e microbiológicas do chorume foram realizadas pelo laboratório ACQUA, segundo Standard Methods for the Examination of Water and Wastewater 22a edição, 5210 B. Os maiores índices de crescimento e de germinação foram obtidos nos substratos: T1; T2; T3; T4 e T5(40\%) nas sementes de feijão, couve e pimenta. Sendo assim, O chorume pode ser utilizado como biofertilizante nas diferentes culturas testadas, pois o mesmo com até $40 \%$ de concentração ocasionou um crescimento significativo das estruturas vegetativas das variedades experimentadas. Isso é corroborado com relação as altas concentrações de DBO e DQO, pois o solo pulverizado com o chorume, reteve a matéria orgânica presente no composto, assim transmitindo estes nutrientes para as plantas, o que ocasionou sua maturação biológica.

\section{The applicability of manure from organic biofertilizer composting process for sustainable agriculture}

The objective of this study was to evaluate the efficiency of manure from organic waste composting process, in different percentages, in the irrigation of three different crops: Georgian Cabbage (Brassica oleracea var. Acephala), Malagueta Pepper (Capsicum frutescens' Malagueta) ') and beans (Phaseolus vulgaris). The mounting of the windrow took place at the CEUMA University Environmental Practices Laboratory. The experimental period was from March 16 to May 16,2018, lasting 60 days, based on Góes et al. (2011) adapted. In all, 33 treatments were performed and organized as follows for each culture: T1 - 100\% H2O; T2 - 10\% slurry; T3 - 20\% manure; T4 - 30\% manure; T5 - 40\% manure; T5 - 50\% manure; T6 - 60\% of manure; T7 - 70\% manure; T8 - $80 \%$ manure; T9 - 90\% manure; T10 $100 \%$ manure. The soil used to plant the crops had the physicochemical parameters analyzed in the Physics Laboratory of the State University of Maranhão - UEMA following the methodology of EMBRAPA, 2017. The physicochemical and microbiological analyzes of the slurry were performed by the laboratory ACQUA, according to Standard Methods for the Examination of Water and Wastewater 22nd edition, $5210 \mathrm{~B}$. The highest growth and germination rates were obtained in the substrates: T1: T2; T3; T4 and T5 (40\%) in bean, cabbage and pepper seeds. Thus, the slurry can be used as biofertilizer in the different cultures tested, because it up to $40 \%$ concentration, caused a significant growth of the vegetative structures of the tested varieties. This is corroborated with the high concentrations of BOD and COD, because the soil sprayed with the slurry retained the organic matter present in the compost, thus transmitting these nutrients to the plants, which caused their biological maturation.

Keywords: Germination; Organic waste; Toxicity.

Topic: Desenvolvimento, Sustentabilidade e Meio Ambiente

Reviewed anonymously in the process of blind peer

Rafaelle Fonseca Cruz

Faculdade Laboro, Brasil

http://lattes.cnpq.br/0362646494456823

http://orcid.org/0000-0002-6720-5890

rafaellefonseca.c@hotmail.com

Osman José de Aguiar Gerude Neto (D)

Universidade Federal do Maranhão, Brasil

http://lattes.cnpq.br/1199184922159968

http://orcid.org/0000-0003-3979-1922

stephfreitaseng@gmail.com

Stephanie Jael Negrão de Freitas

Universidade Federal do Pará, Brasi

http://lattes.cnpq.br/1432769722634758

http://orcid.org/0000-0001-9917-5342

negro.stephanie@gmail.com

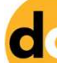

DOI: 10.6008/CBPC2318-2881.2019.003.0005
Received: 08/09/2019

Approved: 10/11/2019

\author{
Jeferson Botelho Rodrigues (iD) \\ Faculdade Laboro, Brasil \\ http://lattes.cnpq.br/9702846379230129 \\ http://orcid. org/0000-0001-6371-7912 \\ botelhojef@gmail.com
}

Déborah Luisa Lucas da Silva (iD)

Universidade Federal de Minas Gerais, Brasi

http://lattes.cnpq.br/8072636625402382

http://orcid.org/0000-0003-3982-5926

dehhluisa@gmail.com

Referencing this:

CRUZ, R. F.; GERUDE NETO, O. J. A.; FREITAS, S. J. N.; RODRIGUES, J. B.; SILVA, D. L. L.. A aplicabilidade do chorume oriundo do processo de compostagem biofertlizante orgânico para agricultura sustentável. Nature and Conservation, v.12, n.3, p.37-48, 2019. DOI: http://doi.org/10.6008/CBPC2318-2881.2019.003.0005 


\section{INTRODUÇÃO}

O crescimento demográfico no mundo, gera necessidade de intensificação na produção de insumos alimentícios. Desta forma, sendo diretamente proporcional ao um maior acúmulo de resíduos gerados pelo homem. Os resíduos orgânicos são constituídos por insumos de atividades humanas presentes no dia a dia, podendo ter diversas origens como: doméstica, agrícola e saneamento básico. São resíduos que no meio ambiente equilibrado, se degradam espontaneamente, mas em áreas urbanas podem ser um grave problema ambiental, se transformando em vetores de doenças e causadores de poluição.

A compostagem por sua vez, degrada este resíduo produzindo assim, um composto orgânico que pode ser utilizado na agricultura como adubo orgânico. O composto orgânico é o material obtido da compostagem; possui cor escura, é rico em ácido húmico (húmus) e contém de 50\% a 70\% de matéria orgânica. É classificado como adubo orgânico, pois é preparado a partir de estercos de animais e/ou restos de vegetais que, em estado natural, não têm valor agrícola. Recebe esse nome pela forma como é preparado: montam-se pilhas compostas de diferentes camadas de materiais orgânicos. A composição do composto orgânico, depende da natureza da matéria-prima utilizada (EMBRAPA, 2004).

Com sua degradação natural, esse resíduo tende a produzir um líquido viscoso e escuro que recebe o nome de chorume, ele pode ser originado de três formas: da umidade natural do lixo, da água de constituição da matéria orgânica, durante o processo de decomposição, como também da decomposição das bactérias existentes nos resíduos. O chorume é um líquido gerado no interior de uma grande acumulação de resíduos, caracterizado por possuir elevados valores de DQO (demanda química de oxigênio) e DBO (demanda bioquímica de oxigênio) (SERAFIM et al., 2003).

Quando o chorume é despeço em aterros e lixões de maneira não controlada, ele provoca vários danos ambientais como, contaminação do solo e lençóis freáticos, altera a qualidade do ar pois o mesmo produz gases, atrai diversas enfermidades. Mas quando separados na fonte (ou seja, quando os resíduos orgânicos não são misturados com outros tipos de resíduos) a reciclagem dos resíduos orgânicos e sua transformação em adubo ou fertilizante orgânico pode ser feita em várias escalas e modelos tecnológicos (BRASIL, 2018).

A compostagem ajuda na segregação de resíduos orgânicos e os demais, a compostagem "é um processo controlado de decomposição microbiana, de oxidação e de oxigenação de uma massa heterogênea de matéria orgânica no estado sólido e úmido" (CAPRARA et al., 2015). Com esse processo controlado, podese utilizar o chorume também de forma controlada como biofertilizante, ajudando assim as culturas se desenvolver. O biofertilizante é produto líquido derivado da degradação da matéria orgânica e por ser rica dela, resulta em um grande poder de fertilização. Desta forma, surge a necessidade de pesquisas como está, cujo foco está em estudar o potencial da biofertilização em culturas.

O presente estudo tem por objetivo avaliar o acréscimo de níveis de porcentagem do chorume oriundo do processo de compostagem de resíduos orgânicos, na rega de três culturas distintas: Couve Manteiga da Geórgia (Brassica oleracea var. acephala), Pimenta Malagueta (Capsicum frutescens 
'Malagueta') e grãos de Feijão (Phaseolus vulgaris), assim testando-o como biofertilizante natural.

\section{MATERIAIS E METÓDOS}

Esta pesquisa apresenta um estudo experimental voltado para a utilização do chorume como biofertilizante em diversos teores, de natureza aplicada e explicativa com abordagem qualitativa. $O$ estudo foi realizado no Laboratório de Práticas Ambientais, do departamento de Engenharia Ambiental, localizado na cidade de São Luís, nas instalações da Universidade Ceuma, no bairro Turú. A pesquisa foi realizada com o intuito de avaliar o comportamento do chorume como biofertilizante em diferentes diluições (0\% à 100\%), diluído água e chorume e assim sendo aplicado em três tipos de espécies vegetais: Couve Manteiga da Geórgia (Brassica oleracea var. acephala), lote: 109414-002- S2, Pimenta Malagueta (Capsicum frutescens 'Malagueta'), lote: 108170-001-S2 e Grãos de Feijão (Phaseolus vulgaris).

Para a extração do chorume, foi confeccionada uma leira com resíduos orgânicos composta de: resíduos de poda (grama e folhas), resíduos de alimentos utilizadas pelo curso de Gastronomia, na cozinha escola do campus Renascença, da Uniceuma, e fezes bovinas oriundas do curral da Universidade Estadual do Maranhão - UEMA. A montagem da leira ocorreu no Laboratório de Práticas Ambientais da Universidade CEUMA, sendo o período experimental de 16 de março até o dia 16 de maio de 2018, compreendendo um período experimental de 60 dias, baseado em Góes et al. (2011) adaptado.

Quadro 1: Tratamentos, com quantitativo de água e chorume para a rega das culturas.

\begin{tabular}{|l|l|l|}
\hline Tratamentos & Quantitativo em $\mathrm{ml}$ de água e chorume & Porcentagem (\%) de água e chorume \\
\hline T1 & $20 \mathrm{ml}$ de água & $100 \%$ de água \\
\hline T2 & $18 \mathrm{ml}$ de água e $2 \mathrm{ml}$ de chorume & $90 \%$ de água e $10 \%$ de chorume \\
\hline T3 & $16 \mathrm{ml}$ de água e $4 \mathrm{ml}$ de chorume & $80 \%$ de água e $20 \%$ de chorume \\
\hline T4 & $14 \mathrm{ml}$ de água e $6 \mathrm{ml}$ de chorume & $70 \%$ de água e $30 \%$ de chorume \\
\hline T5 & $12 \mathrm{ml}$ de água e $8 \mathrm{ml}$ de chorume & $60 \%$ de água e $40 \%$ de chorume \\
\hline T6 & $10 \mathrm{ml}$ de água e 10 de chorume & $50 \%$ de água e $50 \%$ de chorume \\
\hline T7 & $8 \mathrm{ml}$ de água e $12 \mathrm{ml}$ de chorume & $40 \%$ de água e $60 \%$ de chorume \\
\hline T8 & $6 \mathrm{ml}$ de água e $14 \mathrm{ml}$ de chorume & $30 \%$ de água e $70 \%$ de chorume \\
\hline T9 & $4 \mathrm{ml}$ de água e $16 \mathrm{ml}$ de chorume & $20 \%$ de água e $80 \%$ de chorume \\
\hline T10 & $2 \mathrm{ml}$ de água e $18 \mathrm{ml}$ de chorume & $10 \%$ de água e $90 \%$ de chorume \\
\hline T11 & $20 \mathrm{ml}$ de chorume & $100 \%$ de chorume \\
\hline
\end{tabular}

Após estas etapas experimentais, foram retiradas as amostras de chorume, onde o mesmo era escoado através de calha para um recipiente coletor, e armazenado em garrafas plásticas vedadas para a manutenção da pureza do material. A semeadura das espécies foi feita em cachepot de metal com dimensões: $6 \times 4 \times 7 \mathrm{~cm}$, contendo solo coletado na Universidade Ceuma, no campus Turú, e 3 sementes (orientação dos fabricantes) de cada cultura da marca que receberam a denominação $\mathrm{X}$ e $\mathrm{Y}$. Ao todo foram realizados 33 tratamentos (Quadro 1) sendo onze para cada cultura, seguindo porcentagem de $0 \%$ à $100 \%$ de chorume, com as diluições explicadas no quadro.

Após o solo coletado, houve a necessidade de estudar as características químicas $(\mathrm{pH}$, matéria orgânica, fósforo, potássio, sódio, cálcio, alumínio e manganês) e físicas (densidade do solo, densidade das partículas, granulometria e porosidade), do solo presente no campus Turu. As mesmas foram analisadas no laboratório de química e no laboratório de física dos solos da Universidade Estadual do Maranhão (UEMA), 
seguindo os métodos da Embrapa (2017). As amostras foram secas pelo método TFSA (terra fina seca pelo ar), após foram passadas por uma peneira de $2 \mathrm{~mm}$ e são cachimbadas, para assim, haver os ataques com soluções para avaliar o teor total de cada parâmetro.

\section{Análises químicas do solo}

\section{Potencial Hidrogeniônico $(\mathrm{pH})$}

Para a análise do $\mathrm{pH}$, foram adicionadas as amostras $25 \mathrm{ml}$ de $\mathrm{CaCl}_{2}$ (cloreto de cálcio) com $10 \mathrm{ml}$ de solo, pois em grama não é ressaltante ao processo, após foi agitada em mesa agitadora por $10 \mathrm{~min}$, foi feito a leitura no pHmetro através de eletrodos mergulhados na amostra.

\section{Matéria Orgânica}

A matéria orgânica, foi adicionada em solução sulfocrômica agitou-se por 10 minutos, onde foi retirado o sobrenadante e analisado no espectrofotômetro com o comprimento de onda de $650 \mathrm{~nm}$.

\section{Sódio e potássio}

Após foi ataque para determinar a quantidade de sódio e potássio, foi adicionado $25 \mathrm{ml}$ da solução de Mehlich, de onde é retirado $5 \mathrm{ml}$ de sobrenadante e após é feito a leitura pelo fotômetro.

\section{Fósforo}

Para o parâmetro fósforo, foi pesado $2,5 \mathrm{ml}$ de solo e adicionado $100 \mathrm{ml}$ da solução de Mehlich, $10 \mathrm{ml}$ de molibdato de amônio e $30 \mathrm{mg}$ de ácido ascórbico, e assim feita sua leitura no espectrofotômetro através do programa de computador concentration, com o comprimento de onda de 660nm.

\section{Cálcio, alumínio e magnésio}

A análise do cálcio, alumínio e magnésio, ocorre através da extração da solução $\mathrm{KCl} 1 \mathrm{~N}$, misturada ácido etilenodiaminotetracético (EDTA) 0,025 mol L-1, originalmente na cor avermelhada e após adicionada se torna azul assim obtendo o resultado pelo uso do espectrofotômetro.

\section{Análises físicas do solo: Densidade}

A densidade é calculada através da relação entre a massa da amostra do solo seco e da soma do volume das partículas e dos poros, onde são colocados em anéis volumétricos e assim pesando a amostra e calculado através da equação a seguir:

$$
\text { Ds }=\frac{\text { Massa }}{\text { Volume }} \quad \text { Equação: } 1
$$

\section{Densidade das partículas ou porosidade}

A densidade das partículas é calculada através da relação entre a massa da amostra do solo e o 
volume ocupado pela amostra, onde a massa é obtida por pesagem em balança analítica e o volume através de balão volumétrico, é adicionada álcool etílico para a determinação do volume do liquido deslocado pela massa do solo.

$$
\text { Ps }=\frac{\text { Massa do solo }}{\text { Volume do solo }}
$$

Equação: 2

\section{Granulometria}

A granulometria corresponde a distribuição e do tamanho das partículas que constitui o solo, também chamadas de frações granulométricas, que são divididas em três tipos: areia, silte e argila. A análise é feita pela pesagem de $20 \mathrm{~g}$ de solo (TFSA), adiciona $100 \mathrm{ml}$ de água deionizada, $10 \mathrm{ml}$ de hidróxido de sódio e $10 \mathrm{ml}$ de hexametafosfato de sódio, após agitada, passada por peneira. A mesma é levada para a estufa para que haja a evaporação, em seguida é levada ao dessecador, e assim, é feita a determinação das frações do solo.

Segundo Tiquia et al. (1996), avaliar a fitotoxicidade dos compostos é um dos critérios mais importantes a ser usado para evitar riscos ambientais antes que esses compostos podem ser reciclados de volta para terras agrícolas. Baseado em seu estudo, para foram feitas as mesmas diluições e semeadura em placas de Petri (Gráfico 1) para mensurar o índice de germinação das culturas com as diferentes diluições.

As Placas foram regadas diariamente com $3 \mathrm{ml}$ das diluições de água e chorume, após 5 dias foi contado o número de sementes germinadas (Gráfico 2) e medido através de régua o crescimento da raiz (Gráfico 3) expresso em centímetros. Foi utilizada a equação do índice de germinação (GI) para mensurar usando esses dois parâmetros coletados (TIQUIA et al., 1996).

$$
\boldsymbol{G I}=\frac{\boldsymbol{n}^{\mathrm{o}} \text { de sementes germindas } x \text { crescimento da raiz }}{100 \%} \quad \text { Equação: } 3
$$

As análises heterotróficas do chorume foram realizadas no Laboratório de Ciências do Ambiente LACAM da Universidade Ceuma, utilizando 3 meios de culturas: MH (Müeller Hinton), BDA (Batata - Dextrose - Ágar) e BH (Bushnell Hass), para haver uma contagem das colônias de bactérias, onde foram divididos em aeróbios restritos e anaeróbios. Nos anaeróbios foi utilizado a Jarra de Gaspar, que retira o ar na jarra, fazendo com que haja o crescimento apenas de microrganismos anaeróbios.

Após o desenvolvimento inicial das mudas, foi possível mensurar a altura, comprimento da raiz, número de folhas e diâmetro de caule, com 60 dias do experimento. A altura da muda e comprimento de raiz, foi medida através de trena e régua, o número de folhas foram contadas e o diâmetro do caule foi medido por um paquímetro em milímetros seguindo Góes et al. (2011).

Em seguida das medições acima citas, foram realizadas as análises físico-químicas e microbiológicas do chorume utilizado no laboratório ACQUA, localizado na Rua dos Angicos / Angelins Qd. J, n 4a - Jardim Renascença I - São Luís / MA, a ACQUA realiza análises físico-químicas e microbiológicas e presta consultoria no processo de tratamento de água e efluentes.

Parâmetros como DBO (demanda bioquímica de oxigênio), DQO (demanda química de oxigênio), OD (oxigênio dissolvido), turbidez, $\mathrm{pH}$, salinidade, condutividade elétrica, sólidos totais, cloreto, amônia, nitrato 
e nitrito, para que assim seja possível averiguar se o chorume é tóxico ou não, e sua influência no crescimento das espécies em diferentes concentrações.

\section{Análises do chorume: Demanda bioquímica de oxigênio (DBO)}

A DBO consiste no método de encher com amostra, ou diluições apropriadas desta, até transbordar, um frasco com volume específico e incubar em temperatura adequada $\left(20^{\circ} \mathrm{C}+/-1^{\circ} \mathrm{C}\right)$ por 5 dias. O OD (Oxigênio Dissolvido) é medido inicialmente e depois de incubado. A DBO é calculada pela diferença entre o OD inicial e o OD final (depois de 5 dias de incubação) (Standard Methods for the Examination of Water and Wastewater 22a edição, 5210 B).

\section{Demanda química de oxigênio (DQO)}

A DQO, a amostra é aquecida por duas horas com um forte agente oxidante, dicromato de potássio. Os compostos orgânicos oxidáveis reagem, reduzindo o íon de dicromato (Cr2O72) para o íon crômico verde $\left(\mathrm{Cr}^{3+}\right)$. Com este método, a quantidade de $\mathrm{Cr}^{6+}$ amarelo remanescente é determinada. O reagente DQO também contém íons de prata e mercúrio. A prata é um catalisador e o mercúrio é utilizado para complexar interferências do cloreto. Os resultados do teste são medidos a 348 nm (HACH 10211 Método de digestão por reator).

\section{Oxigênio dissolvido (OD)}

A leitura de oxigênio dissolvido (OD) é realizada usando um eletrodo do tipo polarográfico que incorpora uma membrana de material orgânico com seus dois eletrodos, anodo de cloreto de prata e um catodo de platina, onde, o espaço existente entre os mesmos é preenchido com uma solução eletrolítica que proporciona uma reação química de redução gerando uma corrente difusa que habilita o instrumento analisador determinar o teor de Oxigênio Dissolvido na amostra (Standard Methods for the Examination of Water and Wastewater 23a edição, 4500 G Membrane Electrode Method).

\section{Turbidez}

A turbidez de uma amostra de água é o grau de atenuação de intensidade que um feixe de luz sofre ao atravessá-la (esta redução dá-se por absorção e espalhamento, uma vez que as partículas que provocam turbidez nas águas são maiores que o comprimento de onda da luz branca), devido à presença de sólidos em suspensão, tais como partículas inorgânicas (areia, silte, argila) e de detritos orgânicos, algas e bactérias, plâncton em geral, etc..

O Turbidimetro é o instrumento que realiza essa medida, construído basicamente por uma fonte luminosa, cubeta de amostra e fotodetector, instalado em ângulo de 45ㅇ ou 90ำ em relação à fonte de luz (Standard Methods for the Examination of Water and Wastewater 23a edição, 2130 - B Nephelometric Method). 
$\mathrm{pH}$

Para o pH, o princípio básico da medição de pH é a determinação da atividade dos íons hidrogênio por uma medida potenciométrica, usando um eletrodo padrão para íons $\mathrm{H}^{+}$e um eletrodo de referência (Standard Methods for the Examination of Water and Wastewater 23ㄹ edição, 4500-B Electrometric Method).

\section{Salinidade}

Para determinar a salinidade, foi utilizado métodos indiretos envolvendo a medição de uma propriedade física, como condutividade, densidade, velocidade do som ou índice de refração (Método de Condutividade Elétrica).

\section{Condutividade elétrica}

A condutividade é a expressão numérica da capacidade de uma água conduzir a corrente elétrica. Depende das concentrações iônicas e da temperatura e indica a quantidade de sais existentes na coluna d'água e, portanto, representa uma medida indireta da concentração de poluentes (Standard Methods for the Examination of Water and Wastewater 23a edição/ 2510-B).

\section{Sólidos Totais}

Para avaliar os sólidos totais, uma porção homogênea da amostra de volume adequado é transferida quantitativamente para um becker tratado, a amostra é então evaporada em chapa elétrica e seca em estufa à temperatura de 103 a 105ํ․ O aumento de peso em relação ao peso da cápsula vazia corresponde ao resíduo total (Standard Methods for the Examination of Water and Wastewater 23a edição. 2540 A,B).

\section{Cloreto}

O princípio da análise de cloreto é a titulometria. A amostra é titulada com solução padronizada de Nitrato de prata usando o Cromato de potássio como indicador. O Cromato de potássio de colocação amarela reage com o Nitrato de Prata produzindo o Cromato de Prata de colocação vermelho Tijolo. O método é indicado para faixas de concentração de no mínimo 5,0 mg/L de Cl (Standard Methods for the Examination of Water and Wastewater 23a edição. 4500-Cl. B).

\section{Amônia}

Para a amônia, os íons de amônia reagem sob o pH 12.6 com íons de hipocloreto e íons de salicilato na presença de nitroprussida de sódio como catalisador para formar o indofenol. A quantidade de cor formada é diretamente proporcional à quantidade de amônia presente na amostra. Os resultados do teste foram medidos a 690 nm (HACH 10205 Método de salicilato). 
Nitrito

Os nitritos na amostra reagem com o ácido sulfanílico para formar um sal de diazônio intermediário. Ele se une ao ácido cromotrópico para produzir um complexo de coloração rosa diretamente proporcional à quantidade de nitrito presente. Os resultados do teste são medidos a 507 nm (HACH 8507 Método de diazotização).

\section{Nitrato}

Para o nitrato, o metal cádmio reduz os nitratos na amostra para nitrito. $\mathrm{O}$ íon de nitrito reage com em meio ácido com ácido sulfanílico para formar um sal de diazônio intermediário. O sal se une ao ácido cromotrópico para formar um produto de coloração rósea. Os resultados do teste foram medidos a $507 \mathrm{~nm}$ (HACH 8171 Cadmium Reduction Method).

\section{RESULTADOS}

De acordo com os resultados obtidos nas análises do solo e do chorume, observou-se que os diferentes tratamentos influenciaram no desenvolvimento das culturas em 60 dias. Os maiores índices de crescimento e de índice de germinação foram obtidos nos substratos: T1(0\%), T2(10\%), T3(20\%), T4(30\%), T5(40\%) nas sementes de feijão, couve e pimenta. Na análise de altura da muda (Gráfico 1), observou-se o melhor resultado, no tratamento T1 feijão ( $0 \%$ de chorume) com $37 \mathrm{~cm}, \mathrm{~T} 2$ couve $(10 \%) \mathrm{com} 11 \mathrm{~cm}$, e T3 pimenta (20\%) com $9 \mathrm{~cm}$.

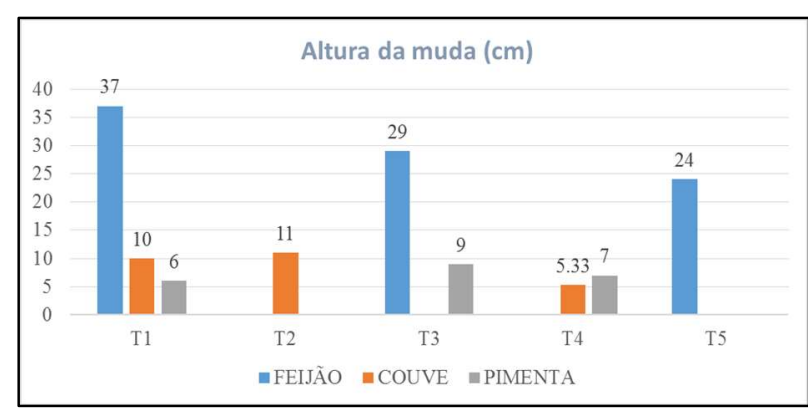

Gráfico 1: Altura da muda.

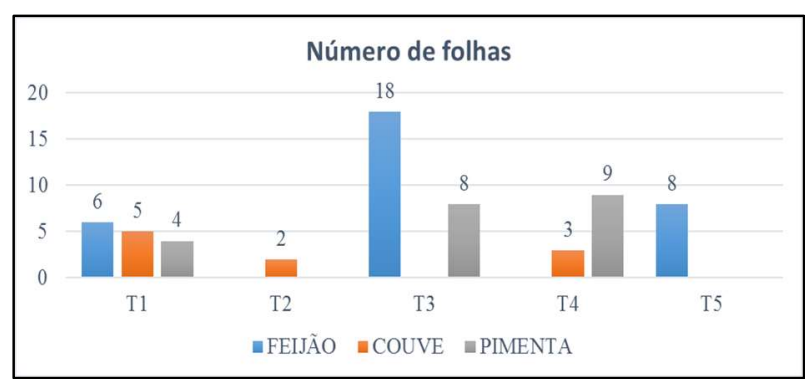

Gráfico 3: Número de Folhas.

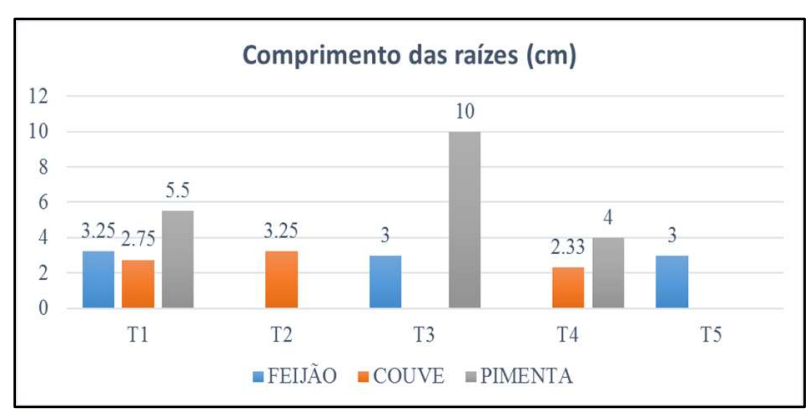

Gráfico 2: Comprimento das raízes.

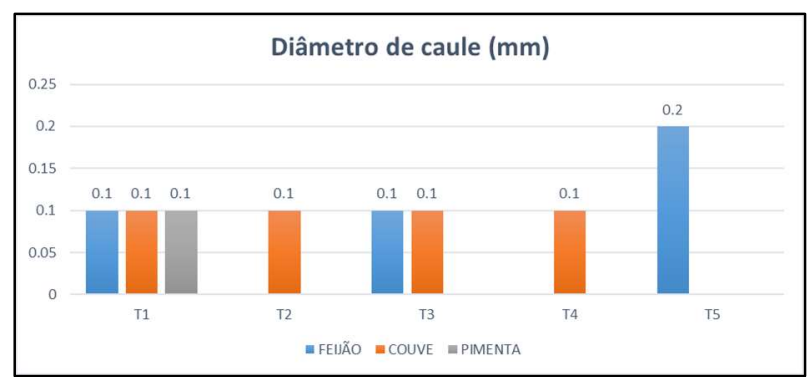

Gráfico 4: Diâmetro do caule.

Para o parâmetro comprimento da raiz (Gráfico 2), as análises apontaram para os tratamentos T1 feijão (0\%) com 3,25 cm, T2 couve (10\%) com 3,25 cm e T3 pimenta (20\%) com $10 \mathrm{~cm}$. O crescimento do número de folhas (Gráfico 3), as análises obtiveram os melhores resultados em T3 feijão (20\%) com 18 folhas, T1 couve (10\%) com 5 folhas e T4 pimenta (30\%) com 9 folhas. 
No que se refere a diâmetro de caule (Gráfico 4) das culturas, o que obteve o melhor resultado foi T5 feijão (40\%) com 0,2 mm, os demais tratamentos obtiveram diâmetro de $0,1 \mathrm{~mm}$. Nos índices de germinação (Gráfico 5), as análises em placa de Petri, obtiveram como melhores resultados foram com a espécie couve manteiga da Geórgia, em T2 (10\%) com 84,8\% e T4 com 84,8\% de germinação.

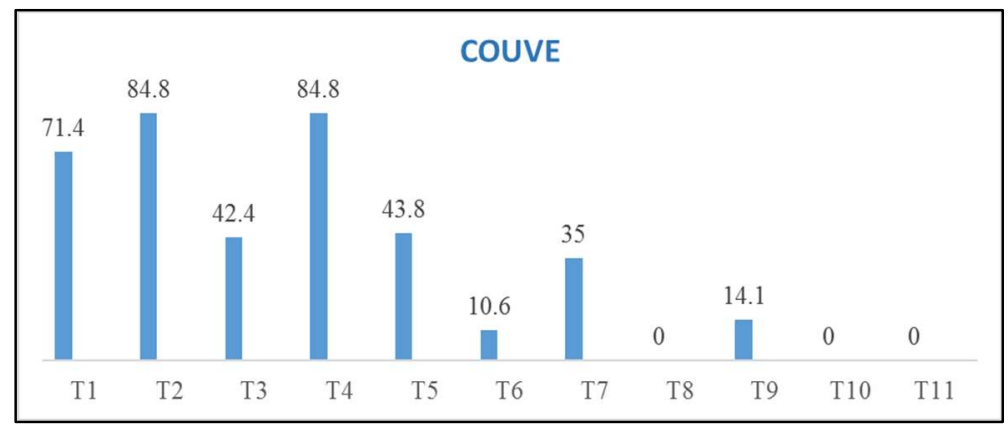

Gráfico 5: Índice de germinação.

\section{Análise química do solo}

Segundo a Embrapa (2006) apresentam importância nos estudos, normalmente agrupados em quatro classes: a) aqueles que indicam os processos do solo ou de comportamento. Ex: pH, Carbono Orgânico; b) aqueles que indicam a capacidade do solo de resistir à troca de cátions. Ex: Tipo de argila (1:1 ou 2:1), CTC, CTA, Óxidos de Ferro; Óxidos de Alumínio; c) aqueles que indicam as necessidades nutricionais das plantas. Ex: N, P, K, Ca, Mg e elementos traços (micronutrientes); d) aqueles que indicam contaminação ou poluição. Ex: Metais pesados, nitrato, fosfato, agrotóxicos. Após a análise químicas do solo (Quadro 2), observou-se que o solo não influenciou pouco nos resultados do crescimento das plantas, já que o mesmo tem baixa matéria orgânica, pH ácido e poucos nutrientes disponíveis no solo, característico do tipo de solo.

Quadro 2: Análise química do solo coletado.

\begin{tabular}{|l|l|}
\hline PARÂMETROS & RESULTADOS \\
\hline $\mathrm{pH}$ & 6,7 \\
\hline Matéria orgânica & $2,3 \%$ \\
\hline Fósforo & $8,0 \mathrm{mg} / \mathrm{dm}^{3}$ \\
\hline Potássio & $0,6 \mathrm{mmol} / \mathrm{dm}^{3}$ \\
\hline Sódio & $2,9 \mathrm{mmol} / \mathrm{dm}^{3}$ \\
\hline Cálcio & $4,3 \mathrm{mmol} / \mathrm{dm}^{3}$ \\
\hline Alumínio & $2,0 \mathrm{mmol} / \mathrm{dm}^{3}$ \\
\hline Magnésio & $9,0 \mathrm{mmol} / \mathrm{dm}^{3}$ \\
\hline Hidrogênio & $1,1 \mathrm{mmol} / \mathrm{dm}^{3}$ \\
\hline CTC & $68,5 \mathrm{mmol} / \mathrm{dm}^{3}$ \\
\hline SB & $55,5 \mathrm{mmol} / \mathrm{dm}^{3}$ \\
\hline $\mathrm{Na} / \mathrm{CTC}$ & $4,2 \%$ \\
\hline Al/Al+SB & $3,5 \%$ \\
\hline $\mathrm{V}$ & $81,0 \%$ \\
\hline
\end{tabular}

\section{Análises físicas do solo}

Do ponto de vista das atividades agrícolas, os indicadores físicos assumem importância por estabelecerem relações fundamentais com os processos hidrológicos, tais como taxa de infiltração, escoamento superficial, drenagem e erosão. Possuem também função essencial no suprimento e armazenamento de água, de nutrientes e de oxigênio no solo (EMBRAPA, 2006). Após as análises físicas 
(Quadro 3 e 4), obteve os resultados dos parâmetros e se observou que o solo apresenta baixa porosidade, menor retenção de água característico do tipo de textura do solo, o que pouco influenciou nos resultados obtidos.

Quadro 3: Granulometria do solo coletado.

\begin{tabular}{|c|c|c|}
\hline \multicolumn{2}{|c|}{ GRANULOMETRIA } & TEXTURA \\
\hline Areia Grossa & $25 \%$ & \multirow{5}{*}{ Franco Arenoso } \\
\hline Areia Fina & $55 \%$ & \\
\hline Silte & $6 \%$ & \\
\hline Argila & $14 \%$ & \\
\hline Silte/Argila & 0,44 & \\
\hline
\end{tabular}

Quadro 4: Análises físicas do solo coletado.

\begin{tabular}{|l|l|}
\hline PARÂMETROS & RESULTADOS \\
\hline Porosidade total & $44 \%$ \\
\hline Densidade do solo & $2,60 \mathrm{~g} . \mathrm{cm}^{-3}$ \\
\hline Densidade das partículas & $1,46 \mathrm{g.cm}$ \\
\hline
\end{tabular}

\section{Análise do chorume}

Após os resultados do chorume (Quadro 5), o pH se apresentou ácido, o que caracteriza chorume em metanogênese, no entanto ainda não foi prejudicial ao desenvolvimento das plantas. Com relação ao DBO do chorume, constatou-se que, o solo teve elevada capacidade de reter a matéria orgânica existente no chorume, havendo assim, o crescimento das plantas. Já DQO apresentou um valor alto, o que indica que contém um valor alto de matéria orgânica no chorume.

Quadro 5: Análise do chorume.

\begin{tabular}{|l|l|}
\hline ANÁLISE & PARÂMETRO \\
\hline DBO & $140 \mathrm{mg} / \mathrm{l}$ \\
\hline DQO & $2.649 \mathrm{mg} / \mathrm{l}$ \\
\hline OD & $<3,50 \mathrm{mg} / \mathrm{l}$ \\
\hline Turbidez & $1.800 \mathrm{UNT}$ \\
\hline pH & 7,47 \\
\hline Salinidade & $2,28 \%$ \\
\hline Condutividade & $3.860 \mu \mathrm{S} / \mathrm{cm}$ \\
\hline Sólidos totais & $3.468 \mathrm{mg} / \mathrm{l}$ \\
\hline Cloreto & $100 \mathrm{mg} / \mathrm{l}$ \\
\hline Amônia & $<0,4 \mathrm{mg} / \mathrm{l}$ \\
\hline Nitrato & $3,8 \mathrm{mg} / \mathrm{l}$ \\
\hline Nitrito & $0,2 \mathrm{mg} / \mathrm{l}$ \\
\hline
\end{tabular}

A turbidez pode estar associada à presença de compostos tóxicos e organismos patogênicos. 0 chorume possui baixa salinidade representando que há altos índices da existência de colônias de bactérias. Já nos valores de cloreto, amônia, nitrato e nitrito consta que no solo há existência de bactérias nitrificantes que produz amônia em nitrato, por isso o valor do nitrato apresentou-se um pouco maior. O valor alto de sólidos totais significa recalcitrância do chorume, a recalcitrância é a incapacidade de degradar um composto, essa recalcitrância estaria relacionada a presença de compostos de massa molecular alta, como é caso de substâncias húmicas presentes no chorume. 


\section{DISCUSSÃO}

Estudos mostram que diferentes culturas podem ter afinidade ou não com os biofertilizantes, no caso além do chorume, existem outros biofertilizantes citados por Paes (2015), originados de esterco animal, ervas, fornecendo energia através de melaço, garapa ou açúcar mascavo, como super magro, biofertilizante de ervas nativas e esterco de vaca, calda bordaleza, calda sulfocálcica, calda viçosa para agricultura orgânica, biofertilizante agrobio.

Em uma análise de potencialidade do solopara efluentes de biodigestor e utilizou-se de um latossolo roxo com $12 \%$ de declividade e exposição Norte. Da análise dos resultados e nas condições que se desenvolveu o estudo, concluiu-se que o efluente de biodigestor aplicado em anos consecutivos promove um melhor condicionamento do solo e um melhor desenvolvimento das plantas.

Nunes et al. (2015), desenvolveu uma pesquisa com fertilizante orgânico (chorume) coletando no processo de vermicompostagem (esterco bovino leiteiro) realizado por minhocas da Califórnia (Eisenia foetida). Para o comprimento de raiz o tratamento (25\%) chorume foi o mais favorável para a produção de mudas de mostarda em sistema de bandejas flutuantes. Os dados foram submetidos à análise de variância e as médias ao teste Duncan ao nível de 5\% de probabilidade utilizando o programa SASM-Agri (2001). Estudos conduzidos por pesquisadores da Embrapa (2015) demonstraram que produtos oriundos do húmus podem exercer atividades bioestimulantes responsáveis pelo crescimento vegetal e podem aumentar a produtividade em até $20 \%$.

\section{CONCLUSÕES}

Dornelles et al. (2015), inferem que o chorume pode ser utilizado como biofertilizante, fornecendo nutrientes e água para as plantas, reduzindo assim, a utilização de fertilizantes químicos e sua potencialidade poluidora. Portanto esta pesquisa reforça a assertiva dos autores, pois o chorume pode ser utilizado como biofertilizante nas diferentes culturas testadas, pois o mesmo com até $40 \%$ de concentração, ocasionou um crescimento significativo das estruturas vegetativas das variedades experimentadas. Isso é comprovado com relação as altas concentrações de DBO e DQO, pois o solo pulverizado com o chorume, reteve a matéria orgânica presente no composto, assim transmitindo estes nutrientes para as plantas, o que ocasionou sua maturação biológica. Resíduos têm potencial e devem ser valorizados. É evidente a necessidade de mais estudos e inciativas tanto da sociedade civil, governo e iniciativa privada para a produção em larga escala de biofertilizantes, então que esta pesquisa incentive outras não só em escala local, mas a nível global.

\section{REFERÊNCIAS}

BRASIL. Ministério do meio ambiente. Gestão de Resíduos Orgânicos. Brasília: MMA, 2018.

CAPRARA, P. T.; REICHERT, G. A.. A compostagem como alternativa de tratamento de resíduos sólidos urbanos orgânicos: considerações para projetos futuros de unidades de triagem e compostagem. In: CONGRESSO BRASILEIRO DE
GESTÃo AMBIENTAL, 5. Anais. Ibeas, 2015. p.1-2.

EMBRAPA. Empresa Brasileira de Pesquisa e Agropecuária. Indicadores físicos e químicos de qualidade de solo de interesse agrícola. Jaguariúna: Embrapa, 2006.

EMBRAPA. Empresa Brasileira de Pesquisa e Agropecuária. 
Uso da compostagem em sistemas agrícolas

orgânicos. Fortaleza: Embrapa Agroindústria Tropical, 2004.

EMBRAPA. Empresa Brasileira de Pesquisa e Agropecuária. Húmus líquido aumenta produtividade em até $20 \%$. Brasília: EMBRAPA, 2015.

GÓES, G. B.; MELO, I. G. C.; DANTAS, D. J.; ARAÚJO, W. B. M.; ALENCAR, R. D.. Utilização de húmus de minhoca como substrato na produção de mudas de tamarindeiro. Revista Verde, Mossoró, v.6, p.125-131, 2011.

NUNES, P. R. S.; BARROS, R. C.; MACHADO, L. S.; HUBER, A. C. K.. Influência de fertilizante orgânico (chorume) na produção de mudas de mostarda (Brassica juncea (L.) Coss.). In: ENCONTRO DE CIENCIA E TECNOLOGIA IFSUL CAMPUS BAGÉ, 2. Anais. Bagé, 2015.

SERAFIM, A. C.; GUSSAKOV, K. C.; SILVA, F.; CONEGLIAN, C. M. R.; BRITO, N. N.; DRAGONI SOBRINHO, G.; TONSO, S. PELEGRINI, R.. Chorume, impactos ambientais e possibilidades de tratamentos. Rio Claro: Fórum de Estudos Contábeis, 2003.

TIQUIA, S. M.; TAM, N. F. Y.; HODGKIS, I. J.. Effects of composting on phytotoxicity of spent pig-manure sawdust litter. Environmental Pollution, Great Britain, v.93, n.3, p.249-256, 1996.

A CBPC - Companhia Brasileira de Produção Científica (CNPJ: 11.221.422/0001-03) detém os direitos materiais desta publicação. Os direitos referem-se à publicação do trabalho em qualquer parte do mundo, incluindo os direitos às renovações, expansões e disseminações da contribuição, bem como outros direitos subsidiários. Todos os trabalhos publicados eletronicamente poderão posteriormente ser publicados em coletâneas impressas sob coordenação da Sustenere Publishing, da Companhia Brasileira de Produção Científica e seus parceiros autorizados. Os (as) autores (as) preservam os direitos autorais, mas não têm permissão para a publicação da contribuição em outro meio, impresso ou digital, em português ou em tradução. 